\title{
Lead Site V3
}

National Cancer Institute

\section{Source}

National Cancer Institute. Lead Site V3. NCI Thesaurus. Code C90415.

A unipolar electrocardiog ram lead site; the electrode is placed on the anterior chest wall midway between leads V2 and V4. In large and small animals, it is placed over the dorsal spinous process of the 7th thoracic vertebra. 